\title{
Simiaosan alleviates the symptoms of gouty arthritis via the NALP3/IL-1ß pathway
}

\author{
XIANZHEN ZHANG, HUIDENG DING, GANG HU and YING LU \\ Department of Rheumatology, Tongde Hospital of Zhejiang Province, Hangzhou, Zhejiang 310012, P.R. China
}

Received March 2, 2020; Accepted September 28, 2020

DOI: $10.3892 / \mathrm{mmr} .2021 .11862$

\begin{abstract}
Previous studies have suggested that the herbal medicine simiaosan has beneficial effects on gouty arthritis (GA), for which conventional Western medicines are insufficient (particularly in cases of multiple episodes). The objective of the present study was to investigate the mechanism by which simiaosan alleviated the symptoms of GA. Sprague-Dawley rat models of acute GA were successfully established, as verified by pathological analyses. Additionally, an NLR family pyrin domain containing 3 (NLRP3) overexpression vector was constructed and a high transfection efficiency was confirmed by reverse transcription PCR. The following five treatment groups were established: i) Normal control; ii) model + saline; iii) model + simiaosan; iv) model + NALP3-overexpressing adenovirus + simiaosan; and v) model + empty vector adenovirus + simiaosan. The samples from mice in each group were subjected to hematoxylin and eosin (H\&E) staining for assessing the histopathological changes, enzyme-linked immunosorbent assays for determining IL-1 $\beta$ and TGF- $\beta 1$ levels and western blotting for evaluating NALP3 expression. H\&E staining indicated that simiaosan could reduce the infiltration of inflammatory cells, while NALP3 overexpression aggravated the inflammatory response in tissues. Expression levels of IL- $1 \beta$, TGF- $\beta 1$ and NALP3 were significantly higher in the model and the model + NALP3-overexpressing adenovirus + simiaosan groups compared with the normal control group. Levels of IL-1 $\beta$, TGF- $\beta 1$ and NALP3 were significantly lower in the model + simiaosan and model + empty vector adenovirus + simiaosan groups compared with the model group. These results indicated that the effects of simiaosan were mediated through NALP3 inhibition. Therefore, the herbal medicine simiaosan was revealed to possess an ability to
\end{abstract}

Correspondence to: Dr Huideng Ding, Department of Rheumatology, Tongde Hospital of Zhejiang Province, 234 Gucui Road, Xihu, Hangzhou, Zhejiang 310012, P.R. China E-mail: djhda@163.com

Key words: gouty arthritis, NLR family pyrin domain containing 3, IL-1 $\beta$, simiaosan alleviate the symptoms of GA by regulating the NALP3/IL-1 $\beta$ signaling pathway.

\section{Introduction}

Gouty arthritis (GA) is a non-specific inflammatory reaction resulting from urate crystal deposition in joints and surrounding soft tissues (1). It is a common metabolic disease that is directly related to hyperuricemia (2). Gout is common in North America and Western Europe, with prevalence of $1-4 \%$ (3). Acute GA is paroxysmal in nature and often presents as redness, swelling, heat and pain in single joints, limiting mobility; in addition, prominent inflammatory and immune responses are activated. The pain is usually excruciating (it may feel like being cut with a knife or being bitten), requiring medications for relief. The first-line drugs for GA include nonsteroidal anti-inflammatory drugs, colchicine and glucocorticoids (4). Although these Western medicines display good efficacy for treating single episodes of acute GA, they are not so beneficial to the overall prognosis of patients who experience multiple episodes of acute GA owing to the adverse effects on gastrointestinal, hepatic and renal systems after repeated use (5). Therefore, a more rational and effective treatment approach for GA is needed in a clinical setting.

To improve clinical treatment, a combination of Western and Chinese medicines may be useful. The dialectical classification of GA in Chinese medicine is 'damp-heat obstruction', and the treatment is focused on eliminating the heat and dampness as well as improving circulation and detoxification (6). Representative treatments for acute GA include simiaosan as the main component combined with other herbal medicines (6). Our group has previously evaluated the clinical characteristics of 104 patients with acute GA and found that the time required for pain relief was significantly shorter for patients treated with simiaosan + Celebrex $(5.76 \pm 1.43$ days) compared with patients treated with Celebrex alone $(8.01 \pm 1.57$ days; $\mathrm{P}<0.05)$. Decrease in various parameters, such as the serum uric acid level, erythrocyte sedimentation rate and C-reactive protein, was greater in the simiaosan + Celebrex group compared with the control group $(\mathrm{P}<0.05)(7)$.

Acute GA is an acute inflammatory process induced by monosodium urate (MSU) crystals and the monocyte/ macrophage system serves a critical role in GA onset, progression and remission (8). MSU crystals interact with resident 
monocytes/macrophages, which release inflammatory factors, leading to neutrophil chemotaxis and cascading reactions. In particular, IL-1 $\beta$ is a key factor in MSU crystal-induced inflammation (9). Previous studies have revealed that nucleotide-binding oligomerization domain-like receptor 3 (NALP3) promotes IL-1 $\beta$ production and serves an essential role in the onset of gout $(10,11)$. TGF- $\beta 1$ is considered an important anti-inflammatory factor implicated in the spontaneous remission of gout (12). An animal model of acute GA was established to investigate the therapeutic efficacy of simiaosan (7). Using this model, the effects of simiaosan on the NALP3/IL-1 $\beta$ pathway were evaluated. The results served as evidence supporting the use of Chinese medicine for the treatment of acute GA (7).

\section{Materials and methods}

Experimental animals. A total of 25 specific-pathogen-free (SPF)-grade male Sprague-Dawley (SD) rats (weight, 200-250 g; age, 8 weeks) were purchased from Changzhou Cavens Lab Animal Co., Ltd., China [license number: SCXK (Xiang) 2016-0002]. Rats (Jiangsu Sinorda Biomedicine Co., Ltd.) were maintained at $20-26^{\circ} \mathrm{C}$ with $40-70 \%$ humidity, 12-h light/dark cycles, and free access to food and water. All methods were approved by the Ethics Committee of Tongde Hospital of Zhejiang Province.

Main reagents and instruments. Sodium urate (cat. no. S16N8I46625; Shanghai Yuanye Bio-Technology Co., Ltd.); Rat IL-1 $\beta$ ELISA kit (cat. no. m1003057; Shanghai Enzyme-linked Biotechnology Co., Ltd.); Rat TGF- $\beta 1$ ELISA kit (cat. no. m1002856; Shanghai Enzyme-linked Biotechnology Co., Ltd.); TRIzol ${ }^{\circledR}$ Reagent (Thermo Fisher Scientific, Inc.); Ultrapure RNA Extraction kit (cat. no. CW0581M; CWBIO); HiFiScript cDNA First-Strand Synthesis kit (cat. no. CW2569M; CWBIO); UltraSYBR mixture (cat. no. CW0957M; CWBIO); PVDF membrane (cat. no. IPVH00010; EMD Millipore); mouse monoclonal Anti-GAPDH (cat. no. TA-08; OriGene Technologies, Inc.; 1:2,000); rabbit polyclonal anti-NALP3 (cat. no. bs-6655R; BIOSS; 1:300); Hypersensitive luminescent solution (cat. no. 340776: Thermo Fisher Scientific, Inc.); microplate reader (RT-6100; Rayto Life and Analytical Sciences Co., Ltd.); PCR instrument (TCT8-II; Shanghai Tocan Biotechnology Co., Ltd.); ultrasensitive chemiluminescence imaging system (Chemi Doc XRS+; Bio-Rad Laboratories, Inc.); fluorescence PCR instrument (CFX Connect real-time; Bio-Rad Laboratories, Inc.); vertical gel electrophoresis instrument (DYY-6C; Beijing Liuyi Instrument Factory); and light microscope (CX41; Olympus Corporation).

Simiaosan powder consisted of the following components: The dried bark of Phellodendron chinense Schneid. (class Dicotyledonae, family Rutaceae), inner bark layer of Berberis, which is processed into fried Atractylodes (class Dicotyledon, order Chrysanthemum, family Compositae), Semen Coicis, the seed of Coix (order Poales, family Poaceae) and Achyranthes, a perennial herb (order Caryophyllales, family Amaranthaceae). The herbal medicine simiaosan was prepared by combining $9 \mathrm{~g}$ of Phellodendron bark, $12 \mathrm{~g}$ of fried Atractylodes, $30 \mathrm{~g}$ of Semen Coicis and $15 \mathrm{~g}$ of two-toothed Achyranthes root in a rice cooker. After cooking in boiling water for $30 \mathrm{~min}$ at 9 o'clock in the morning, the liquid was retained. Subsequently, the medicine was cooked again in boiling water for $30 \mathrm{~min}$ in the afternoon and the liquid was again retained. The liquids from two preparations were mixed and concentrated to $0.55 \mathrm{~g} / \mathrm{ml}$.

Construction of acute GA models. SD rats were weighed and $330 \mathrm{mg} / \mathrm{kg} 10 \%$ chloral hydrate was administered via intraperitoneal injection. None of the SD rats exhibited decreased appetite, mental weakness, or clinical manifestations of peritonitis, including abdominal wall tension, palpation avoidance, or resistance. There were no abnormal mortalities during the trial. The joint circumference of the right hind ankle was measured while bent at a $90^{\circ}$ angle in all rats at the same location by wrapping a thread around the joint and was recorded as the circumference before modeling $(0 \mathrm{~h})$. SD rats were fixed in a supine position and the joint of the right hind ankle was disinfected with iodophor. A 6-mm injection needle was inserted into the dorsum of the joint at a $45^{\circ}$ angle into the inner surface of the tibial tendon until a space was identified. Subsequently, $100 \mu 1$ of $3.0 \%$ sodium urate solution was injected (a preparation of 3\% sodium urate: $0.06 \mathrm{~g}$ of sodium urate was weighed and dissolved in $2 \mathrm{ml}$ of physiological saline to form a $3 \%$ sodium urate suspension, which was mixed by agitation). The injection continued until swelling of the contralateral joint capsule was observed and the acute GA rat model was constructed.

Construction of the NALP3 overexpression vector. The cDNA fragment of $N A L P 3$ was PCR amplified using restriction enzyme site (ClaI/ClaI) (Bsu15I (ClaI); cat. no. ER0141; Thermo Fisher Scientific, Inc.) NALP3 was cloned into the PDS_166 pAd-CMV-GFPa1-IRES vector (cat. no. D6950-01; Omega Bio-Tek, Inc.). DH5 $\alpha$ cells $\left(50 \mathrm{ml} ; 2 \times 10^{9} \mathrm{cells} / \mathrm{ml}\right.$; cat. no. 9057; Takara Bio, Inc.) were transfected with $1 \mathrm{ng}$ plasmids encoding the $N A L P 3$ s for $16 \mathrm{~h}$ (media-Luria-Bertani; cat. no. HB0128; Qingdao Hope Bio-Technology Co., Ltd.). The plasmid NALP3-PDS_166 pAd-CMV-GFPa1-IRES was separated by $1 \%$ agarose gel electrophoresis. Following enzyme digestion, expansion was continued to ensure a high purity and in vitro cell transfection was performed using Lipofectamine ${ }^{\circledR} 2000$ (Invitrogen; Thermo Fisher Scientific, Inc.), following the manufacturer's instructions. The NALP3 adenovirus expression solution was obtained and processed using an adenovirus packaging system.

Experimental groups. The $25 \mathrm{SPF}$-grade SD rats were randomly divided into five groups: i) Normal control; ii) model + saline (saline was administered intragastrically at a concentration of $10.8 \mathrm{ml} / \mathrm{kg}$ for two consecutive weeks); iii) model + simiaosan (simiaosan at a concentration of $0.55 \mathrm{~g} / \mathrm{ml}$ was administered intragastrically at a dose of $5.94 \mathrm{~g} / \mathrm{kg}$, a concentration of $10.8 \mathrm{ml} / \mathrm{kg}$, for two consecutive weeks); iv) model + NALP3 -overexpressing adenovirus + simiaosan (the joint cavity was injected with $10 \mu \mathrm{l}$ of NALP3-overexpressing adenovirus and simiaosan at a concentration of $0.55 \mathrm{~g} / \mathrm{ml}$ was administered intragastrically at a dose of $5.94 \mathrm{~g} / \mathrm{kg}$, a concentration of $10.8 \mathrm{ml} / \mathrm{kg}$, for two consecutive weeks); and v) model + empty vector adenovirus + simiaosan (the joint cavity was injected 
Table I. Primer information.

\begin{tabular}{llccc}
\hline Primer name & \multicolumn{1}{c}{ Primer sequence $\left(5^{\prime}-3^{\prime}\right)$} & $\begin{array}{c}\text { Primer } \\
\text { length }(\mathrm{bp})\end{array}$ & $\begin{array}{c}\text { Amplicon } \\
\text { length (bp) }\end{array}$ & $\begin{array}{c}\text { Annealing } \\
\text { temperature }\left({ }^{\circ} \mathrm{C}\right)\end{array}$ \\
\hline NALP3 F & AGCCTCAGGGCACCAAA & 17 & 443 & 57.8 \\
NALP3 R & GGGATGAAGCACATAGTAAACAG & 23 & & 58.6 \\
GAPDH F & GCAAGTTCAACGGCACAG & 18 & 141 & \\
GAPDH R & CGCCAGTAGACTCCACGAC & 19 & & \\
\hline
\end{tabular}

F, forward; R, reverse.

with $10 \mu \mathrm{l}$ of empty vector adenovirus and simiaosan at a concentration of $0.55 \mathrm{~g} / \mathrm{ml}$ was administered intragastrically at a dose of $5.94 \mathrm{~g} / \mathrm{kg}$, a concentration of $10.8 \mathrm{ml} / \mathrm{kg}$, for two consecutive weeks).

Quantitative fluorescence $(Q F) P C R$. The joint fluid was extracted from the rats in the control, NALP3-overexpressing adenovirus and empty vector adenovirus groups. The cells were isolated and RNA was extracted with Ultrapure RNA Extraction kit (cat. no. CW0581M; Beijing ComWin Biotech Co., Ltd.) from the joint fluid in each group. Following RNA extraction, $0.2 \mathrm{ml}$ of chloroform was added and the mixture was centrifuged at $4^{\circ} \mathrm{C}$ and $13,400 \mathrm{x}$ g for $15 \mathrm{~min}$. The colorless aqueous phase was transferred to the same volume of $70 \%$ pre-cooled ethanol and mixed. The solution was added to the adsorption column of the collection tube for centrifugation and drying. The adsorption column was added to a new 1.5-ml pre-cooled RNase-free centrifuge tube. RNase-free water $(35 \mu \mathrm{l})$ was added to fully dissolve the RNA. The RNA was obtained after two rounds of centrifugation at $13,400 \mathrm{x} \mathrm{g}$ at $4^{\circ} \mathrm{C}$ for $1 \mathrm{~min}$ and was stored at $-80^{\circ} \mathrm{C}$. The extracted RNA was used to synthesize cDNA using a reverse transcription kit, following the manufacturer's protocol. The cDNA was used as a template for real-time PCR. GAPDH was used as an internal control to calculate the relative expression levels of NALP3 in each group. Primer information is presented in Table I.

The QF-PCR mixture was comprised of $9.5 \mu \mathrm{l}$ of RNasefree $\mathrm{dH}_{2} \mathrm{O}, 1 \mu \mathrm{l}$ of cDNA/DNA, $1 \mu \mathrm{l}$ of upstream primer, $1 \mu \mathrm{l}$ of downstream primer and $12.5 \mu 1$ of $2 \mathrm{X}$ GoldStar Taq MasterMix (cat. no. CW0957M; Beijing ComWin Biotech Co.).

The QF-PCR protocol was as follows: 40 cycles of predenaturation at $95^{\circ} \mathrm{C}$ for $3 \mathrm{~min}$, denaturation at $95^{\circ} \mathrm{C}$ for $10 \mathrm{sec}$, annealing at $53^{\circ} \mathrm{C}$ for $30 \mathrm{sec}$ and extension at $72^{\circ} \mathrm{C}$ for $30 \mathrm{sec}$, followed by a final extension at $72^{\circ} \mathrm{C}$ for $10 \mathrm{~min}$. Bio-Rad CFX Manager (version 3.0; Bio-Rad Laboratories, Inc.) was used to analyze the data.

Histopathological analysis. Synovial tissue samples obtained from the joint cavity were rinsed under running water for $2 \mathrm{~h}$ and then dehydrated using a graded ethanol series at 70, 80 and $90 \%$. A mixture with equal volumes of pure alcohol and xylene was added to the tissue samples and the samples were incubated for $15 \mathrm{~min}$, followed by the addition of xylene I for $15 \mathrm{~min}$ and xylene II for $15 \mathrm{~min}$ at $20-26^{\circ} \mathrm{C}$ (until the tissues were translucent). A mixture comprising equal volumes of xylene and paraffin wax was then added for $15 \mathrm{~min}$. Paraffin I and paraffin II were added and the samples were incubated for $50-60 \mathrm{~min}$ to allow wax infiltration at $20-26^{\circ} \mathrm{C}$. The tissues were then paraffin-embedded and sectioned into $4-\mu \mathrm{m}$ thick sections. The paraffin sections were heated and then dewaxed and hydrated with distilled water. When the sections were hydrated, they were placed in an $0.5 \%$ aqueous solution of hematoxylin and stained for $3 \mathrm{~min}$. Hydrochloric acid in ethanol was added for $15 \mathrm{sec}$ for differentiation, followed by quick rinsing with water, addition of bluing solution for $15 \mathrm{sec}$, rinsing with water, $0.5 \%$ eosin staining for $3 \mathrm{~min}$ at $20-26^{\circ} \mathrm{C}$, rinsing with water, dehydration, clearing, and sealing with neutral resin. Subsequently, synovial membranes were observed in three randomly selected regions using a light microscope (magnification, $\mathrm{x} 200$ ).

Determination of serum IL-1 and TGF-1 levels by ELISA. The IL-1 and TGF-1 contents in the serum of rats in each group were detected using an ELISA kit. Optical density (OD) at $450 \mathrm{~nm}$ was measured using a microplate reader. The concentration of the standard substance and OD values were used to generate a standard curve and to obtain a linear regression equation. The OD values for each sample were then used to calculate the contents of IL-1 and TGF-1 (pg/ml).

Determination of NALP3 level in joint fluid by western blotting. Ankle fluid from the hind foot and lower leg of rats in each group was collected. Following lysis centrifugation, the supernatant was absorbed and the protein was extracted by RIPA lysis buffer (cat. no. C1053; Applygen Technologies, Inc.). A BCA kit was used to determine the protein concentration. Following total protein ( $4 \mu \mathrm{g}$ per lane) denaturation and electrophoresis (12\% SDS-PAGE), samples were transferred onto a PVDF membrane, which was blocked with 5\% fat-free milk at $4{ }^{\circ} \mathrm{C}$ overnight, and then incubated with a rabbit polyclonal anti-NALP3 primary antibody (cat. no. bs-6655R; BIOSS; 1:300) at $4^{\circ} \mathrm{C}$ overnight. Subsequently, the membranes were incubated with a HRP-conjugated Affinipure goat anti-rabbit IgG $(\mathrm{H}+\mathrm{L})$ secondary antibody (cat. no. ZB-2301; OriGene Technologies, Inc.; 1:2,000) at $20-26^{\circ} \mathrm{C}$ for $2 \mathrm{~h}$, followed by exposure and development (hypersensitive luminescent solution; cat. no. RJ239676; Thermo Fisher Scientific, Inc.). Quantity One software (version 4.5; Bio-Rad Laboratories, Inc.) was used to analyze the gray values for each antibody strip, draw standard curves and calculate the protein concentrations of the samples in $\mu \mathrm{g} / \mu 1$. 


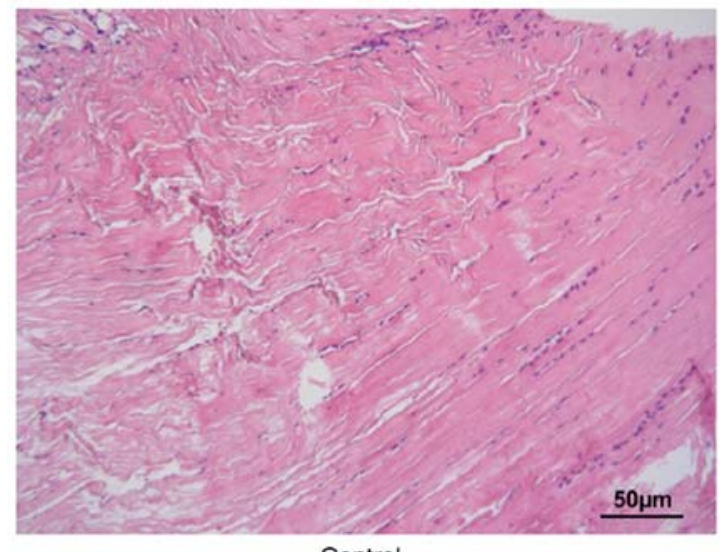

Control

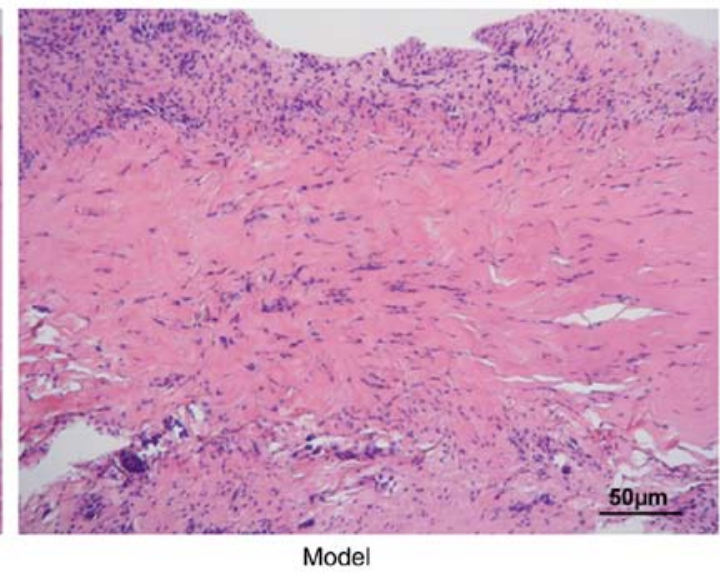

Model

Figure 1. Validation of the successful establishment of a rat model of gouty arthritis by histopathologic analysis (magnification, x200).

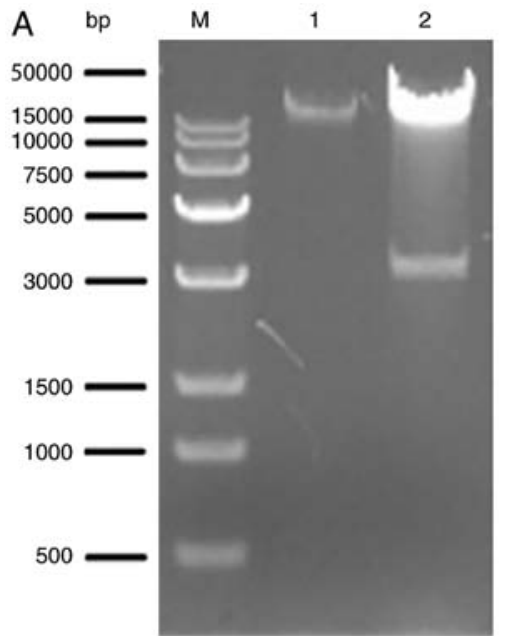

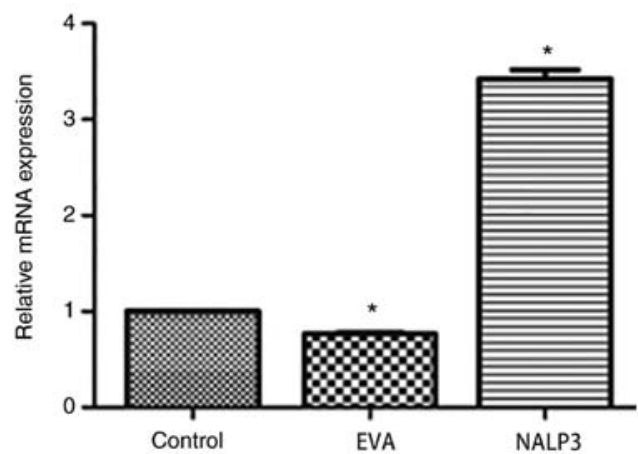

Figure 2. Construction of an NALP3 overexpression vector and validation of the transfection efficiency. (A) Validation of the NALP3 overexpression vector. (B) Validation of the transfection efficiency. "P<0.05 vs. the NC group. NALP3, nucleotide-binding oligomerization domain-like receptor 3; NC, normal control.

Animal care. Animal care and all experimental procedures were performed in accordance with the Guide for the Care and Use of Laboratory Animals published by the US National Institutes of Health (publication no. 85-23, revised 1996). The handling of rats and all experimental procedures were approved by the Institutional Animal Care and Use Committee of Tongde Hospital of Zhejiang Province. The following humanitarian thresholds were used: i) Weight loss (rats losing 15-20\% of their body weight rapidly); ii) loss of appetite (rats that did not eat for 24-36 h or ate only a small amount of food for 3 days); and iii) body organ infection (abnormal physical indicators and blood tests indicated the failure of drug treatment and the development of systemic disease). At the end of the experiment, after collecting the body fluids and tissues samples, all rats were euthanized by complete anesthesia with inhalation of $3 \%$ halothane followed by cervical dislocation. Mortality was confirmed by checking whether the heart of the animals had stopped completely and the pupils were dilated.

Statistical analysis. All data were analyzed using SPSS 19.0 (IBM Corp.). One-way ANOVA followed by Bonferroni's post hoc test was used to determine significant differences among rat groups. $\mathrm{P}<0.05$ was considered to indicate a statistically significant difference.

\section{Results}

Pathological validation of model establishment. As revealed in Fig. 1, the synovial tissues in the model group exhibited more extensive inflammatory cell infiltration compared with the normal control group, indicating successful establishment of the experimental model.

Construction of the NALP3 overexpression vector and validation of the transfection efficiency. The expected band sizes for the plasmid NALP3-PDS_166 pAd-CMV-GFPa1-IRES cleaved by ClaI were 35,184 and 3,120 bp. As revealed in Fig. 2A, the electrophoresis results were consistent with the anticipated values, demonstrating that the correct plasmid was obtained. As revealed in Fig. 2B, the expression of NALP3 in the NALP3-overexpression group was significantly higher compared with the empty vector adenovirus group $(\mathrm{P}<0.05)$. 


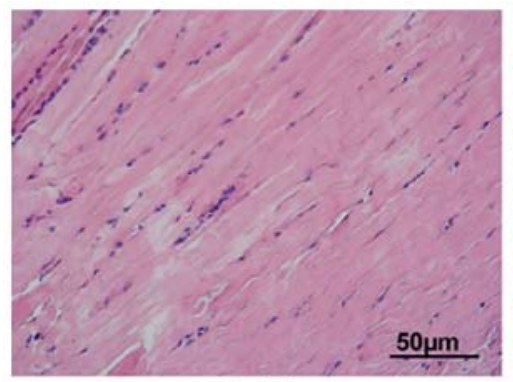

Control

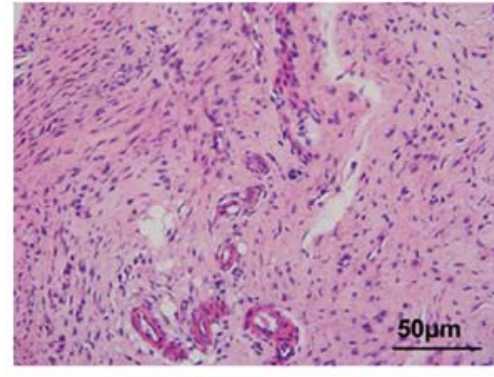

NALP3 + Simiaosan

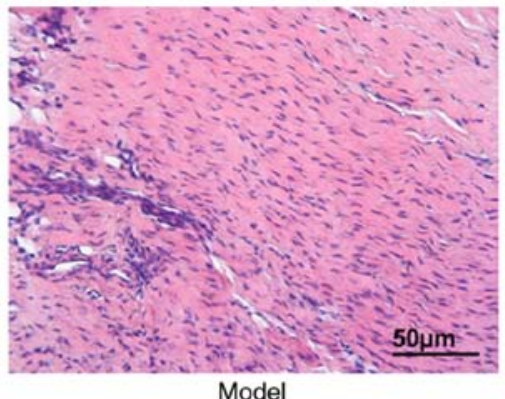

Model

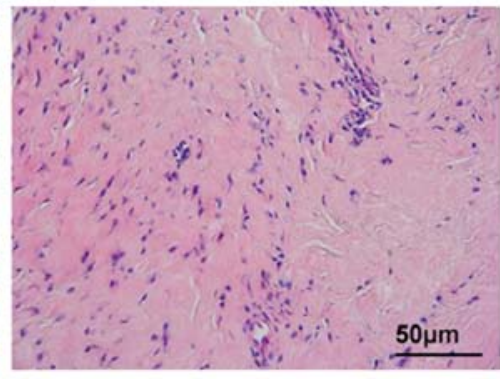

NC+Simiaosan

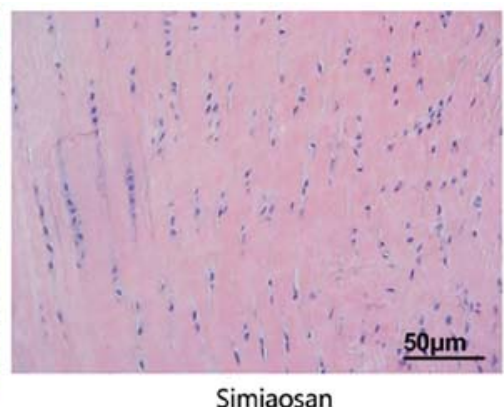

Simiaosan

Figure 3. Hematoxylin and eosin staining of the tissue samples from each treatment group (magnification, x200). NALP3, nucleotide-binding oligomerization domain-like receptor 3; NC, normal control.
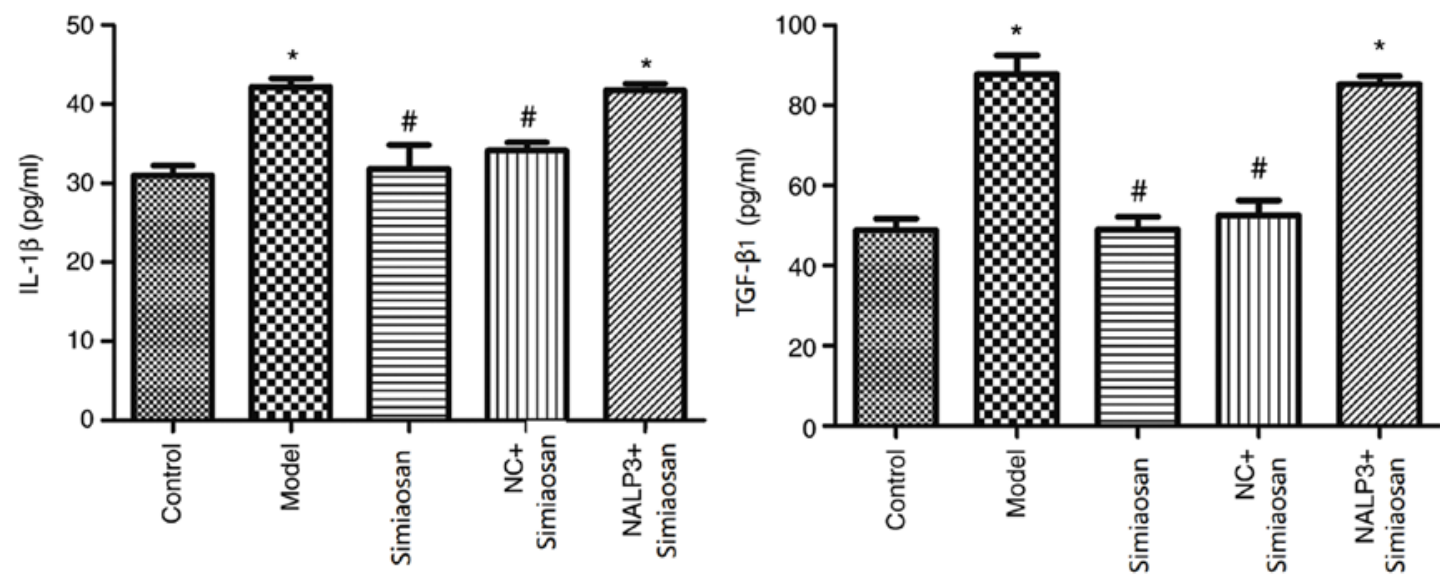

Figure 4. IL-1 $\beta$ and TGF- $\beta 1$ expression levels in each treatment group ( ${ }^{*} \mathrm{P}<0.05$ vs. the control group; ${ }^{\#} \mathrm{P}<0.05$ vs. the model group). NALP3, nucleotide-binding oligomerization domain-like receptor 3; NC, normal control.

Hematoxylin and eosin $(H \& E)$ staining. As revealed in Fig. 3, the synovial tissues in the model group exhibited extensive inflammatory cell infiltration. The synovial tissues in the model + simiaosan group were neatly arranged without discernable infiltration of inflammatory cells, unlike those in the model group. The model + NALP3-overexpressing adenovirus + simiaosan group exhibited a significantly higher inflammatory cell count and the model + empty vector adenovirus + simiaosan group exhibited a lower extent of inflammatory cell infiltration compared with the model group. These findings indicated that simiaosan may reduce inflammatory cell infiltration, whereas NALP3 aggravates the inflammatory response in tissues.

Expression of $I L-1 \beta$ and TGF- $\beta 1$. As revealed in Fig. 4, compared with the levels in the normal control group, the expression levels of IL-1 $\beta$ and TGF- $\beta 1$ were significantly higher in the model and the model + NALP3-overexpressing adenovirus + simiaosan group $(\mathrm{P}<0.05)$. Compared with the levels in the model group, the expression levels of IL-1 $\beta$ and TGF- $\beta 1$ were significantly lower in the model + simiaosan and the model + empty vector adenovirus + simiaosan groups $(\mathrm{P}<0.05)$.

Expression of NALP3. As revealed in Fig. 5, the expression of NALP3 was significantly higher in the model and the model + NALP3-overexpressing adenovirus + simiaosan groups compared with the model control group $(\mathrm{P}<0.05)$. The expression of NALP3 was significantly lower in the model + simiaosan and the model + empty vector adenovirus + simiaosan groups compared with the model group $(\mathrm{P}<0.05)$. 

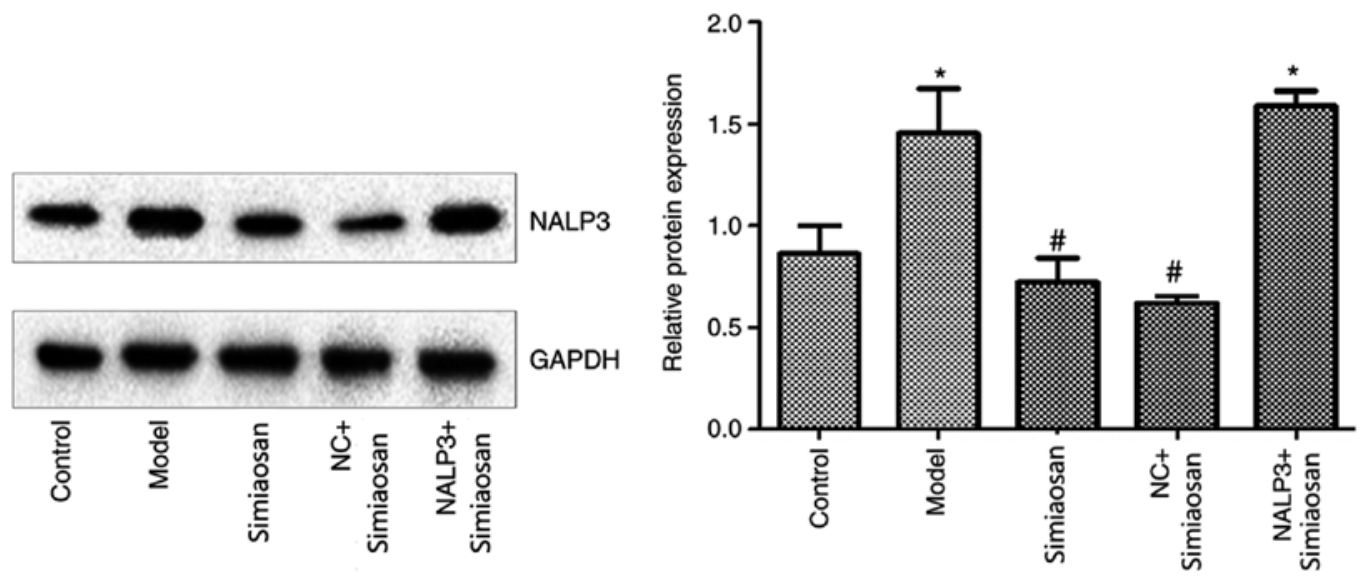

Figure 5. NALP3 expression in each treatment group ( ${ }^{*} \mathrm{P}<0.05$ vs. the control group; ${ }^{*} \mathrm{P}<0.05$ vs. the model group). NALP3, nucleotide-binding oligomerization domain-like receptor 3; NC, normal control.

\section{Discussion}

GA, one of the most common forms of autoimmune arthritis, is characterized biochemically by hyperuricemia, leading to the repeated deposition of MSU in joint cavities and synovial tissue (1). The development of GA can be roughly divided into two phases. The first phase involves the processing and maturation of IL-1 $\beta$, in which mononuclear phagocytes phagocytose and internalize MSU, leading to the activation of NALP 3 complex and the synthesis, processing and release of IL-1 $\beta$. The processing and maturation of IL-1 $\beta$ are primarily related to the activity of the NALP 3 complex. The second phase comprises IL-1 $\beta$-induced recruitment. In this phase, a series of chemical factors and inflammatory mediators are generated via the activation of ILReceptor/myeloid differentiation primary response 88 on the surface of non-bone marrow-derived cells $(13,14)$. This induces neutrophil chemotaxis toward the joint cavity, leading to an acute inflammatory process characterized by neutrophil infiltration, that is, the onset of a GA episode (15).

IL-1 $\beta$ is an inflammatory factor synthesized by monocytes or macrophages. The precursor form is implicated in certain chronic inflammatory diseases, such as rheumatoid arthritis (16). However, studies have found that compared to other inflammatory factor inhibitors (such as TNF- $\alpha$ inhibitors), IL-1 inhibitors are less effective in improving the clinical symptoms of rheumatoid arthritis, indicating that IL-1 $\beta$ does not serve a key role in the pathogenesis of rheumatoid arthritis $(17,18)$. However, a previous study revealed that IL-1 $\beta$ may serve a critical role in the pathogenesis of GA (19). Liu (20) reported that simiaosan can effectively relieve the symptoms of GA.

In the present study, an acute GA model was established using sodium urate. The synovial tissue of the model group exhibited extensive inflammatory cell infiltration, indicating successful establishment of the experimental model. Similarly, extensive inflammatory cell infiltration was observed in the synovial tissue of the model group and treatment with simiaosan improved the condition of synovial tissues, whereas NALP3 aggravated the inflammatory response. Furthermore, NALP3 expression was significantly reduced in the simiaosan group. These results demonstrated that the beneficial effects of simiaosan on GA are mediated by NALP3 inhibition.

A recent study on the treatment of gout arthritis by inhibiting the activation of NALP 3 complex also confirmed the important role of NALP 3 complex in the inflammatory process of gout (21). In the present study, simiaosan downregulated the expression of IL- $1 \beta$ and TGF- $\beta 1$, while the overexpression of NALP3 led to increased levels of IL-1 $\beta$ and TGF- $\beta 1$. These findings indicated that simiaosan can alleviate the symptoms of GA to a certain extent by downregulating the NALP3/IL-1 $\beta$ pathway. In summary, simiaosan can alleviate the symptoms of GA and may exert its effect by regulating the NALP3/IL-1 $\beta$ signaling pathway.

\section{Acknowledgements}

Not applicable.

\section{Funding}

This study was supported by the Zhejiang TCM Science and Technology Project (grant no. 2017ZA023).

\section{Availability of data and materials}

The datasets used or analyzed during the current study are available from the corresponding author on reasonable request.

\section{Authors' contributions}

$\mathrm{XZ}$ and GH participated in performing the experiments, collecting data and drafted the manuscript. HD performed the statistical analysis and participated in the design of the present study. YL participated in the design of the present study and helped to draft the manuscript. All authors read and approved the final manuscript.

\section{Ethics approval and consent to participate}

This study was carried out in accordance with the recommendations in the Guide for the Care and Use of Laboratory Animals 
of the National Institutes of Health. The animal experiments were performed in accordance with protocols approved by the Institutional Animal Care and Use Committee of Tongde Hospital of Zhejiang Province (approval no. DW2016035).

\section{Patient consent for publication}

Not applicable.

\section{Competing interests}

The authors declare that they have no competing interests.

\section{References}

1. Tausche AK and Aringer M: Gouty arthritis. Z Rheumatol 75 885-898, 2016 (In German).

2. Cleophas MC, Crisan TO and Joosten LA: Factors modulating the inflammatory response in acute gouty arthritis. Curr Opin Rheumatol 29: 163-170, 2017.

3. Kuo CF, Grainge MJ, Zhang W and Doherty M: Global epidemiology of gout: Prevalence, incidence and risk factors. Nat Rev Rheumatol 11: 649-662, 2015.

4. Wilson L and Saseen JJ: Gouty arthritis: A review of acute management and prevention. Pharmacotherapy 36: 906-922, 2016.

5. Ge N, Peng XJ and Zheng YX: Drugs and evaluation for the treatment of acute phase gout. Chinese General Practice 6: 477-478, 2005

6. Wang YJ: Guiding Journal of Traditional Chinese Medicine and Pharmacy 3: 89-90, 2015.

7. Zhang XZ, Hu G, Huang MC and Ying L: Clinical observation on 104 cases of acute gouty arthritis treated by Simiaosan. Zhejiang J Trad Chin Med 53: 31-32, 2018.

8. Jovanovic DV, Boumsell L, Bensussan A, Chevalier X, Mancini A and Di Battista JA: CD101 expression and function in normal and rheumatoid arthritis-affected human $\mathrm{T}$ cells and monocytes/macrophages. J Rheumatol 38: 419-428, 2011.

9. Mitroulis I, Kambas K and Ritis K: Neutrophils, IL-1 $\beta$, and gout: Is there a link? Semin Immunopathol 35: 501-512, 2013.

10. Martinon F, Pétrilli V, Mayor A, Tardivel A and Tschopp J: Gout-associated uric acid crystals activate the NALP3 inflammasome. Nature 440: 237-241, 2006.
11. Yang G, Lee HE, Moon SJ, Ko KM, Koh JH, Seok JK, Min JK, Heo TH, Kang HC, Cho YY, et al: Direct binding to NLRP3 pyrin domain as a novel strategy to prevent NLRP3-driven inflammation and gouty arthritis. Arthritis Rheumatol 72: 1192-1202, 2020.

12. Steiger $S$ and Harper JL: Neutrophil cannibalism triggers transforming growth factor $\beta 1$ production and self regulation of neutrophil inflammatory function in monosodium urate monohydrate crystal-induced inflammation in mice. Arthritis Rheum 65: 815-823, 2013.

13. Martin WJ, Walton M and Harper J: Resident macrophages initiating and driving inflammation in a monosodium urate monohydrate crystal-induced murine peritoneal model of acute gout. Arthritis Rheum 60: 281-289, 2009.

14. Chen CJ, Shi Y, Hearn A, Fitzgerald K, Golenbock D, Reed G, Akira S and Rock KL: MyD88-dependent IL-1 receptor signaling is essential for gouty inflammation stimulated by monosodium urate crystals. J Clin Invest 116: 2262-2271, 2006.

15. Zhang QB, Qing YF, Yin CC, Zhou L, Liu XS, Mi QS and Zhou JG: Mice with miR-146a deficiency develop severe gouty arthritis via dysregulation of TRAF 6, IRAK 1 and NALP3 inflammasome. Arthritis Res Ther 20: 45, 2018.

16. Lopez-Castejon $\mathrm{G}$ and Brough D: Understanding the mechanism of IL-1 $\beta$ secretion. Cytokine Growth Factor Rev 22: 189-195, 2011.

17. Takakubo Y, Barreto G, Konttinen YT, Oki H and Takagi M: Role of innate immune sensors, TLRs, and NALP3 in rheumatoid arthritis and osteoarthritis. J Long Term Eff Med Implants 24: 243-251, 2014.

18. Dinarello CA and van der Meer JW: Treating inflammation by blocking interleukin-1 in humans. Semin Immunol 25: 469-484, 2013.

19. Sil P, Wicklum H, Surell C and Rada B: Macrophage-derived IL-1 $\beta$ enhances monosodium urate crystal-triggered NET formation. Inflamm Res 66: 227-237, 2017.

20. Liu MY: Clinical study of Jiawei Si Miao SAN in the treatment of hyperuricemia and acute gouty arthritis. Liaoning J Trad Chin Med (Chinese Science and Technology Journal Database) 38: 675-677, 2011.

21. Deng W, Yang Z, Yue H, Ou Y, Hu W and Sun P: Disulfiram suppresses NLRP3 inflammasome activation to treat peritoneal and gouty inflammation. Free Radic Biol Med 152: 8-17, 2020.

This work is licensed under a Creative Commons Attribution-NonCommercial-NoDerivatives 4.0 International (CC BY-NC-ND 4.0) License. 